\title{
Um estudo sobre a evasão nos cursos de graduação dos institutos federais
}

\author{
A study on evasion in Federal Institutes graduation courses
}

\author{
Recebido: 20/07/2020 | Revisado: \\ 26/10/2020 | Aceito: 12/03/2021 | \\ Publicado: $16 / 06 / 2021$ \\ Elisângela de Souza \\ ORCID: https://orcid.org/0000-0002-6906- \\ 3822 \\ Instituto Federal de Educação, Ciência e \\ Tecnologia do Mato Grosso(IFMT) \\ E-mail: lisdapaz@hotmail.com \\ Lourdes Francisca Freitas \\ ORCID: https://orcid.org/0000-0002-9634- \\ 3184 \\ Instituto Federal de Educação, Ciência e \\ Tecnologia do Mato Grosso(IFMT) \\ E-mail: Ifrancisca.freitas@gmail.com
}

Como citar: SOUZA, E.; FREITAS, F. L.; Um estudo sobre a evasão nos cursos de graduação dos institutos federais. Revista Brasileira da Educação Profissional e Tecnológica, [S.I.], v. 1, n. 20, p. 1-16 e10757, jun. 2021. ISSN 24471801.

This work is licensed under a Creative Commons Attribution 4.0 Unported License.

\begin{abstract}
Resumo
A evasão nos cursos de graduação é ainda um problema que afeta as instituições brasileiras. Os Institutos Federais de Ciência e Tecnologia ofertam cursos superiores especialmente na área tecnológica. $\mathrm{O}$ artigo apresenta uma análise descritiva dos estudantes matriculados no ensino superior dos Institutos Federais, utilizando os dados do Censo da Educação Superior do Instituto Nacional de Estudos e Pesquisas Educacionais Anísio Teixeira (INEP), com o propósito de observar os perfis de evasão. No período pesquisado, $18,59 \%$ dos universitários que ingressaram naquele ano haviam desistido do curso. Os resultados revelaram que, alguns grupos destacaram-se com proporções maiores de evasão, quando comparados ao total, como por exemplo, estudantes do curso à distância.
\end{abstract}

Palavras-chave: Evasão. Ensino Superior. Institutos Federais.

\begin{abstract}
Evasion in undergraduate courses is still a problem that affects Brazilian institutions. The Federal Institutes of Science and Technology offer higher education courses especially in the technological area. The article presents a descriptive analysis of students enrolled in higher education at Federal Institutes, using data from the Higher Education Census of the National Institute of Educational Studies and Research Anísio Teixeira (INEP), with the purpose of observing dropout profiles. In the period surveyed, $18.59 \%$ of university students who entered that year had dropped out of the course The results revealed that, some groups stood out with higher proportions of dropout, when compared to the total, for example, students of the distance course.
\end{abstract}

Keywords: Evasion. Higher Education. Federal Institution. 


\section{INTRODUÇÃO}

O ensino superior público brasileiro passou por diversas políticas que incentivaram a expansão deste nível, tais como Apoio a Planos de Reestruturação e Ampliação das Universidades Federais (REUNI) em 2007 e a criação em 2008, da Rede Federal de Educação Profissional e Tecnológica (BRASIL, 2007; 2008). Heringer (2008) destacou que o crescimento do ensino superior brasileiro permitiu a entrada de estudantes oriundos de grupos pouco presentes na educação superior. A autora ainda ressaltou que esta inserção ocorreu de forma significativa nas instituições federais de educação superior.

A Lei Federal o 11.892/ 2008, que institui a Rede Federal de Educação Profissional, Científica e Tecnológica, determina que um dos objetivos dos Institutos Federais é ministrar o ensino superior em cursos de tecnologia, licenciatura, bacharelado e engenharia (BRASIL, 2008). Com a ampliação e reestruturação desta rede, novos cursos de graduação surgiram nos institutos.

Apesar do aumento do ingresso de estudantes nos Institutos Federais, uma preocupação é em relação a permanência destes. A Plataforma Nilo Peçanha, que é uma base de disseminação dos dados oficiais da Rede Federal de Educação Profissional, Científica e Tecnológica, informa que as taxas de evasão anual nos cursos superiores nos Institutos Federais nos anos de 2017, 2018 e 2019 são de $17,6 \%, 14,5 \%, 12,7 \%$, respectivamente. Mesmo mostrando um decréscimo nestas taxas, a evasão revela ser um sério obstáculo que afeta as instituições.

O presente artigo busca trazer uma discussão sobre a evasão nos Institutos Federais e apresentar um perfil dos estudantes que evadiram nestas instituições.

Ao realizar um estudo sobre a evasão, procura-se fazer uma análise de como a situação pode impactar as instituições e até mesmo a sociedade, e a partir daí pensar em políticas públicas e ações internas que possam mitigar os efeitos desse fenômeno.

O trabalho transcorre com uma breve abordagem histórica sobre os cursos de graduação nos Institutos Federais e, posteriormente contextualiza a evasão no ensino superior. Na sequência, discorre acerca da metodologia empregada, seguida dos resultados e a consequente discussão. E por fim, são expostas as considerações finais do texto.

\section{OS CURSOS DE GRADUAÇÃO NOS INSTITUTOS FEDERAIS}

A normatização da educação federal profissional teve início com o Decreto $n^{\circ}$ 7566 do ano de 1909, assinado pelo então presidente Nilo Peçanha, que determinou a criação das Escolas de Aprendizes Artífices para o ensino profissional primário gratuito (OTRANTO, 2010). As escolas técnicas federais foram autorizadas no ano de 1969 a oferecerem cursos superiores de tecnologia e a normativa do Conselho Nacional de Educação, o Parecer CNE/CES 436/2001 fez que estes cursos fossem reconhecidos como "cursos de graduação com características especiais, distintos dos tradicionais" (GUERRA; FERRAZ; MEDEIROS, 2019). 
Ao longo dos anos esta rede passou por várias regulamentações e reformulações, até a Lei 11.892/2008, que instituiu a Rede Federal de Educação Profissional, Científica e Tecnológica.

A Rede Federal de Educação Profissional, Científica e Tecnológica contempla atualmente os Institutos Federais de Educação, Ciência e Tecnologia, a Universidade Tecnológica Federal do Paraná - UTFPR; os Centros Federais de Educação Tecnológica Celso Suckow da Fonseca (CEFET-RJ) e de Minas Gerais (CEFET-MG), as Escolas Técnicas Vinculadas às Universidades Federais e o Colégio Pedro II. Nos termos do artigo $2^{\circ}$ da Lei oㅜ 11.892/2008, tem por definição que os Institutos Federais são:

Os Institutos Federais são instituições de educação superior, básica e profissional, pluricurriculares e multicampi, especializados na oferta de educação profissional e tecnológica nas diferentes modalidades de ensino, com base na conjugação de conhecimentos técnicos e tecnológicos com as suas práticas pedagógicas (BRASIL, 2008).

A legislação trouxe como um dos objetivos dos Institutos Federais a oferta de cursos superiores de tecnologia, cursos de licenciatura e bacharelado em engenharia, no que refere aos cursos superiores de graduação. A Lei 11892/2008 estipula que $20 \%$ das vagas referentes à graduação sejam de licenciatura (BRASIL, 2008).

Lima (2013) apontou que as instituições que compõe a Rede Federal de Educação Tecnológica tradicionalmente apresentavam cursos mais específicos do setor técnico-industrial e agropecuário. A autora revelou que a oferta dos cursos de licenciaturas é algo recente, sendo a inclusão do percentual destinado à formação de professores na lei fundamentado pela escassez de docentes.

Na linha de universalizar, não somente o ensino básico, mas também o ensino superior, Souza e Silva (2016) salientaram o papel social dos Institutos Federais, que consta no documento que expõe suas concepções e diretrizes.

O foco dos Instituto Federais será a justiça social, a equidade, a competitividade econômica e a geração de novas tecnologias. Responderão, de forma ágil e eficaz, às demandas crescentes por formação profissional, por difusão de conhecimentos científicos e tecnológicos e de suporte aos arranjos produtivos locais (BRASIL, 2010, p.3).

Sendo assim, o ensino ofertado nos Institutos Federais visa não somente uma preparação para o mercado de trabalho, mas também que este deva ser articulado com as relações sociais, políticas e econômicas. 


\section{EVASÃO NOS CURSOS DE GRADUAÇÃO}

A evasão no ensino superior é um problema que ainda atinge os cursos de graduação. Estudos identificaram possíveis causas que levam os estudantes a evadirem dos cursos, tais como questões relacionadas à infraestrutura da instituição, ausência de interação com professores e colegas, falta de discernimento na tomada de decisão da escolha da carreira, deficiência na educação básica, falta de maturidade, desmotivação com o curso e a futura profissão, razões socioeconômicas, longa distância da faculdade à sua residência e ainda problemas pessoais (BARDAGI;HUTZ, 2005;DIAS;THEOPHILO;LOPES, 2010;LOBO, 2012).

Pela relevância da questão, algumas políticas públicas vieram com o intuito de contribuir direta ou indiretamente para a redução dos índices de evasão. $O$ Programa Nacional de Assistência Estudantil (PNAES), criado em 2010, tem como um dos seus objetivos reduzir as taxas de retenção e evasão. O programa determina ações a serem implementadas nas áreas de moradia estudantil, alimentação, transporte, atenção à saúde; inclusão digital; cultura, esporte; creche; apoio pedagógico e aprendizagem de alunos com deficiência (BRASIL,2010).

O acórdão 506/2013 do Tribunal de Contas da União (TCU) demonstrou que, as taxas de conclusão para o ensino superior representavam na época $25,40 \%$ para a Licenciatura, $27,50 \%$ para o Bacharelado e $42,80 \%$ para os cursos de tecnólogo no país. $\mathrm{O}$ documento observou que as diversas estratégias de combate à evasão, nos campi dos Institutos Federais, ocorriam de forma isolada comparada aos demais. $\mathrm{O}$ TCU recomendou na ocasião, que a Secretaria de Educação Profissional e Tecnológica do Ministério da Educação (SETEC/MEC) instituísse um plano em parceria com os Institutos Federais voltado ao tratamento da evasão (BRASIL, 2013).

No ano de 2014, a SETEC/MEC publicou como retorno ao acórdão 506/2013, o Documento Orientador para a Superação da Evasão e Retenção na Rede Federal de Educação Profissional, Científica e Tecnológica. O texto sugeriu que cada instituto desenvolvesse um Plano Estratégico de Intervenção e Monitoramento para Superação da Evasão e Retenção, no qual as quatro fases apresentariam a seguinte ordem: instituição de comissão interna; elaboração de diagnóstico quantitativo; elaboração de diagnóstico qualitativo e consolidação do plano estratégico (BRASIL, 2014).

Outra ação mais recente da SETEC/MEC foi a publicação da Portaria no 8 de 28 de maio de 2019, que institui e regulamenta a Comissão Permanente de Acompanhamento das Ações de Permanência e o Êxito dos Estudantes da Rede Federal (CPPE). A CPPE tem como finalidade acompanhar e monitorar as ações dos Institutos Federais quanto ao cumprimento dos Planos Estratégicos para Permanência e Êxito dos Estudantes (BRASIL, 2019a).

$O$ indicador Eficiência Acadêmica dos Concluintes (EAC), que aponta a proporção de concluintes frente ao total de matrículas "finalizadas" em cada instituição, seja por conclusão ou por evasão, foi de $50,54 \%$ em 2018 , sendo o maior desde 2015. O EAC desconsidera o número de alunos retidos. O Relatório Anual de Análise dos Indicadores de Gestão das Instituições Federais de Educação Profissional, Científica e Tecnológica apresentou uma expectativa de que com a instituição da CPPE, os indicadores relacionados à permanência e êxito melhorem (BRASIL, 2019b). 
A evasão é uma questão que deve ser tratada com muito cuidado e atenção, tendo em vista que além, de trazer prejuízos para o estudante, pode acarretar em consequências institucionais, sociais e econômicas. Silva Filho et al. (2007) destacaram que a evasão representa uma perda de recursos públicos e no setor privado indica uma perda de receitas.

\section{METODOLOGIA}

A metodologia utilizada no presente artigo trata-se da análise descritiva dos dados do Censo da Educação Superior do Instituto Nacional de Estudos e Pesquisas Educacionais Anísio Teixeira (INEP) do ano 2018, período mais recente até a escrita deste artigo. Segundo Gil (2008), os resultados alcançados na pesquisa exploratória podem auxiliar na identificação das relações entre as variáveis investigadas no estudo.

Os dados dos Institutos Federais também são publicados na Plataforma Nilo Peçanha, porém esta base possui metodologia diferente do Censo da Educação Superior do INEP, não podendo somar os seus resultados (MORAES, 2018). A escolha pela base dos dados do INEP justifica-se por esta apresentar algumas variáveis que não são disponibilizadas na Plataforma Nilo Peçanha.

O levantamento das informações foi feito pelo microdados divulgados no site do INEP. Usou-se a variável "desvinculados do curso" para tratar dos alunos evadidos. Segundo INEP (2019b), os estudantes declarados como desvinculados são aqueles que não ocupam mais vaga na instituição.

A pesquisa apresenta as informações de 40 Institutos Federais, abrangendo - Centro Federal de Educação Tecnológica de Minas Gerais (CEFET MG) e o Centro Federal de Educação Tecnológica Celso Suckow da Fonseca (CEFET-RJ). Cabe ressaltar que o Colégio Pedro II, que também faz parte da Rede Federal, até a coleta dos dados do censo não tinha curso de graduação.

Foram constatados 1572 códigos diferentes de cursos, dessa forma, por fins metodológicos estes serão analisados por área, seguindo o Manual para classificação de cursos de Graduação e sequenciais (INEP, 2019a), que apresenta categorização segundo modelos internacionais.

Para a elaboração da Cine Brasil 2018, adotou-se a metodologia estabelecida para a International Standard Classification of Education - Fields of Education and Training (Isced-F 2013), produzida pela Organização das Nações Unidas para a Educação, a Ciência e a Cultura (Unesco), com adequações à realidade educacional brasileira (INEP, 2019a, p. 13).

A fim de comparabilidade entre o total de alunos e o total de evadidos, para algumas variáveis foram calculadas as razões, que compreende o quociente do número de estudantes evadidos pelo total da linha correspondente. $O$ cálculo utilizado na pesquisa foi adaptado do cálculo adotado por Klein (2003), que determinou a taxa de evasão com os dados do censo escolar do INEP. 
O artigo apresenta apenas a análise exploratória dos dados, pois não foram empregadas técnicas estatísticas inferenciais. A manipulação dos microdados foram realizadas no programa Statistical Package for Social Sciences (SPSS).

A seguir serão expostos os resultados e a discussão da pesquisa.

\section{RESULTADOS E DISCUSSÕES}

Segundo os dados do Censo da Educação Superior de 2018, os Institutos Federais de Educação, Ciência e Tecnologia e Centros Federais de Educação Tecnológica correspondiam a $36,36 \%$ das instituições federais que ofertavam 0 ensino superior no país e continham 14,90\% das matrículas destas (INEP,2019b).

No período estudado, observou-se que somente 10 das 40 instituições têm sua reitoria localizada fora da capital do estado. Quanto à localização dos cursos, apenas $21,06 \%$ estão instalados na capital, enquanto $76,14 \%$ situam-se fora dela. Os cursos à distância, que representam $2,80 \%$ da oferta, não se inserem neste tipo de categorização.

A pesquisa registrou que a maioria dos estudantes estão situados na região Sudeste, com $32,82 \%$ do total, seguida das regiões Nordeste com $31,56 \%$, Sul com $14,92 \%$, Centro-Oeste $12,60 \%$ e Norte com $8,10 \%$.

No ano de 2018, 255.997 estudantes foram declarados pelas Instituições Federais nos cursos de graduação no Censo da Educação Superior, nos quais 44.013 estavam desvinculados do curso, representando $17,19 \%$ do total informado.

O Gráfico 1 traz a proporção de evasão por Grandes Regiões, revelando que a maior desta está localizada na Região Centro-Oeste. A razão apresentada é o quociente do número de evadidos da região pelo número total.

Gráfico 1: Razão entre o número de evadidos pelo total de estudantes por Grandes Regiões

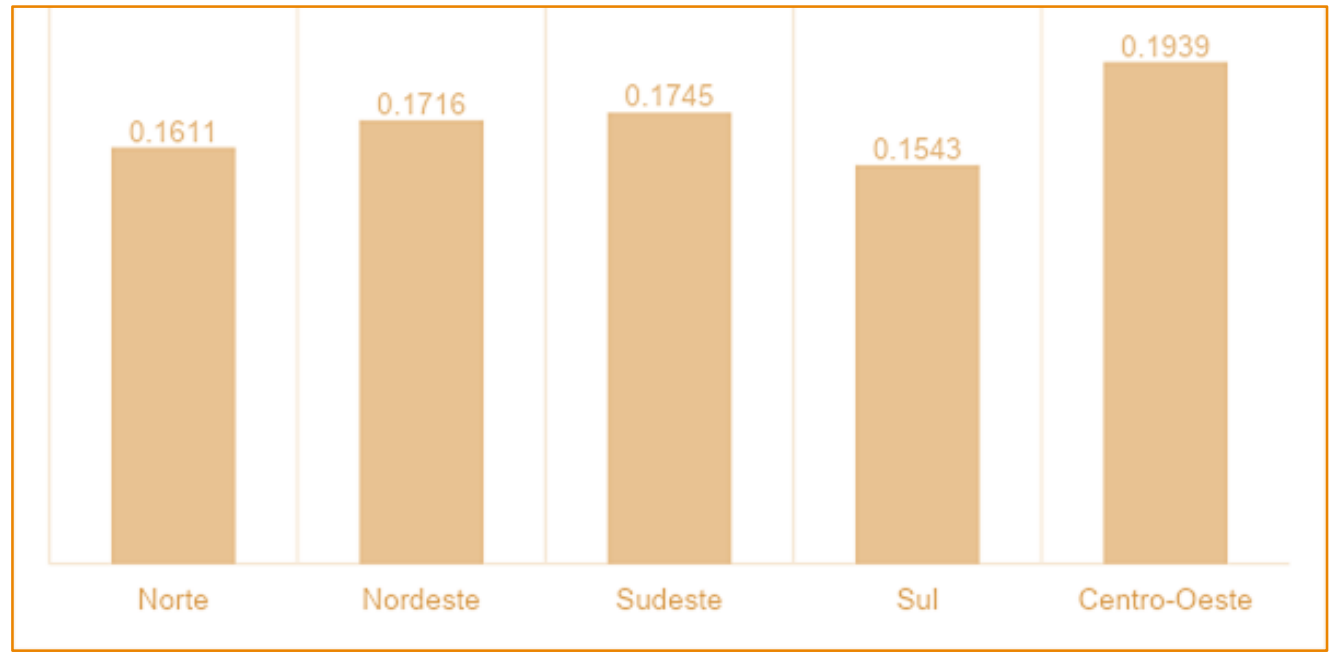

Fonte: INEP. Censo da Educação Superior 2018.Tabulação dos autores. 
A maior parte dos estudantes é do sexo masculino com $56,89 \%$ do total (Tabela 1). Quando se analisa somente os universitários evadidos, este percentual cresce para $60,95 \%$ dos casos, indicando uma proporção de evasão deste grupo maior.

Tabela 1: Distribuição dos estudantes por sexo

\begin{tabular}{|cccccc|}
\hline Sexo & $\begin{array}{c}\text { Total de } \\
\text { estudantes }\end{array}$ & $\%$ & Evadidos & $\%$ & $\begin{array}{c}\text { Razão de } \\
\text { evasão por } \\
\text { sexo }\end{array}$ \\
\hline Feminino & 110.363 & $43,11 \%$ & 17.185 & $39,05 \%$ & 0,156 \\
\hline Masculino & 145.634 & $56,89 \%$ & 26.828 & $60,95 \%$ & 0,184 \\
\hline Total & 255.997 & $100,00 \%$ & 44.013 & $100,00 \%$ & 0,172 \\
\hline
\end{tabular}

Fonte: INEP. Censo da Educação Superior 2018. Tabulação dos autores.

Melo (2008) apontou que razões históricas justificam uma menor presença feminina em carreiras tradicionalmente reconhecidas como masculinas, principalmente nas áreas de ciências exatas, engenharia e computação, que são os cursos predominantes nos Institutos Federais.

O grau bacharelado concentra a maioria dos estudantes dos Institutos Federais, com $36,64 \%$. Porém, quando se observa a taxa de evasão, o grau tecnológico foi maior, conforme ilustra a Tabela 2. Os casos descritos como não aplicáveis referem-se aos cursos da Área Básica de Ingresso (ABI), no qual o estudante primeiro matricula na instituição e posteriormente faz a opção entre duas ou mais formações acadêmicas, após concluir um conjunto básico de disciplinas (INEP, 2019a). Nota-se que o grau tecnológico possui uma razão de evadidos pelo total de estudantes por grau acadêmico maior do que os demais.

Tabela 2: Evasão de acordo com o grau acadêmico

\begin{tabular}{|cccccc|}
\hline Grau & $\begin{array}{c}\text { Total de } \\
\text { estudantes }\end{array}$ & $\%$ & Evadidos & $\%$ & $\begin{array}{c}\text { Razão de } \\
\text { evadidos pelo } \\
\text { total por grau } \\
\text { acadêmico }\end{array}$ \\
\hline Bacharelado & 93.790 & $36,64 \%$ & 12.558 & $28,53 \%$ & 0,134 \\
\hline Licenciatura & 79.959 & $31,23 \%$ & 14.325 & $32,55 \%$ & 0,179 \\
\hline $\begin{array}{c}\text { Tecnológico } \\
\text { Não }\end{array}$ & 81.625 & $31,89 \%$ & 17.005 & $38,64 \%$ & 0,208 \\
\hline $\begin{array}{c}\text { aplicável } \\
\text { Total }\end{array}$ & 623 & $0,24 \%$ & 125 & $0,28 \%$ & 0,201 \\
\hline & 255.997 & $100,00 \%$ & 44.013 & $100,00 \%$ & 0,172 \\
\hline
\end{tabular}

Nota: (*) Não aplicável refere-se aos cursos com Área Básica de Ingresso

Fonte: INEP. Censo da Educação Superior 2018. Tabulação dos autores. 
A Tabela 3 mostra a composição racial dos estudantes. A variável cor ou raça apresenta uma quantidade significativa de não-resposta, situação encontrada também no estudo de Souza (2015). Senkevics, Machado e Oliveira (2016) afirmaram que esta variável indicava, um alto índice de ausência ou de não declaração racial, problemas, tanto entre alunos quanto entre docentes, que vêm diminuindo devido ações do INEP. Excluindo os dados que estão sem a declaração, têm-se que os estudantes que declararam ser pretos, apresentam uma razão do número de evadidos pelo total um pouco maior que os demais.

Tabela 3: Evasão por cor ou raça

\begin{tabular}{|c|c|c|c|c|c|}
\hline Cor ou raça & $\begin{array}{l}\text { Total de } \\
\text { estudantes }\end{array}$ & $\%$ & Evadidos & $\%$ & $\begin{array}{c}\text { Razão de } \\
\text { evadidos pelo } \\
\text { total de por } \\
\text { cor/ raça }\end{array}$ \\
\hline $\begin{array}{c}\text { Não } \\
\text { declarou }\end{array}$ & 30.586 & $11,95 \%$ & 5.430 & $12,34 \%$ & 0,178 \\
\hline Branca & 93.875 & $36,67 \%$ & 16.017 & $36,39 \%$ & 0,171 \\
\hline Preta & 22.568 & $8,82 \%$ & 4.007 & $9,10 \%$ & 0,178 \\
\hline Parda & 103.345 & $40,37 \%$ & 17.723 & $40,27 \%$ & 0,171 \\
\hline Amarela & 3.053 & $1,19 \%$ & 492 & $1,12 \%$ & 0,161 \\
\hline Indígena & 1.520 & $0,59 \%$ & 225 & $0,51 \%$ & 0,148 \\
\hline $\begin{array}{l}\text { Não - } \\
\text { resposta }\end{array}$ & 1.050 & $0,41 \%$ & 119 & $0,27 \%$ & 0,113 \\
\hline Total & 255.997 & $100,00 \%$ & 44.013 & $100,00 \%$ & 0,172 \\
\hline
\end{tabular}

Fonte: INEP. Censo da Educação Superior 2018. Tabulação dos autores.

Os Institutos Federais também ofertam cursos à distância (EaD). Na EaD a evasão é motivada por diversos fatores, alguns peculiares a esta modalidade, como tecnologia inadequada ou falta de habilidade para utilizar esta corretamente (Moore; Kearsley,2008).

Com relação ao turno, destaca-se que os cursos à distância apresentam maior taxa de evasão comparados aos demais (Tabela 4). O trabalho de Almeida et al. (2013), que analisou os cursos à distância oferecidos pelo Centro de Educação a Distância da Universidade de Brasília, observou que estes apresentaram alta taxa de evasão. Os autores apontaram os principais motivos que levaram à evasão na pesquisa, como fatores situacionais, estes relacionados à problemas pessoais; falta de apoio acadêmico; dificuldades com a tecnologia e ausência de apoio administrativo. 
Tabela 4: Evasão de acordo com o turno

\begin{tabular}{|c|c|c|c|c|c|}
\hline Turno & $\begin{array}{c}\text { Total de } \\
\text { estudantes }\end{array}$ & $\%$ & Evadidos & $\%$ & $\begin{array}{c}\text { Razão de } \\
\text { evadidos } \\
\text { pelo total } \\
\text { por turno }\end{array}$ \\
\hline Matutino & 31.937 & $12,48 \%$ & 6.029 & $13,70 \%$ & 0,189 \\
\hline Vespertino & 24.861 & $9,71 \%$ & 4.544 & $10,32 \%$ & 0,183 \\
Noturno & 117.503 & $45,90 \%$ & 21.234 & $48,24 \%$ & 0,181 \\
\hline Integral & 63.850 & $24,94 \%$ & 8.571 & $19,47 \%$ & 0,134 \\
EaD & 17.846 & $6,97 \%$ & 3.635 & $8,26 \%$ & 0,204 \\
\hline Total & 255.997 & $100,00 \%$ & 44.013 & $100,00 \%$ & 0,172 \\
\hline
\end{tabular}

Fonte: INEP. Censo da Educação Superior 2018. Tabulação dos autores.

Em relação a idade dos universitários, a idade mínima foi de 14 anos e a máxima de 84 anos, e para os que desistiram do curso, a mínima foi de 16 anos e a máxima de 76 anos. A idade média de todos os estudantes pesquisados é de 26,44 anos e a mediana de 24 anos, com desvio padrão de 8,091. Enquanto para os evadidos, a idade média é 27,37 anos, a mediana 25 anos e o desvio padrão de 8,501.

Considerando o grupo dos estudantes desvinculados dos cursos de graduação nos Institutos Federais, 47,31\% a faixa etária predominante é dos 19 aos 25 anos, conforme mostra a Tabela 5.

Tabela 5: Faixa etária dos estudantes desistentes

\begin{tabular}{|ccc|}
\hline Idade em anos & $\begin{array}{c}\text { Número de } \\
\text { evadidos }\end{array}$ & $\%$ \\
\hline $\begin{array}{c}\text { Menor ou igual } \\
\text { a 18 }\end{array}$ & 2.432 & $5,53 \%$ \\
\hline 19 a 25 & 20.823 & $47,31 \%$ \\
\hline 26 a 33 & 10.853 & $24,66 \%$ \\
34 a 40 & 5.608 & $12,74 \%$ \\
41 a 47 & 2.776 & $6,31 \%$ \\
48 a 54 & 1.025 & $2,33 \%$ \\
55 a 62 & 391 & $0,89 \%$ \\
63 a 69 & 91 & $0,21 \%$ \\
Maior ou igual a & 14 & $0,03 \%$ \\
\hline 70 & & $100,00 \%$ \\
\hline Total & 44.013 & 10,0 \\
\hline
\end{tabular}

Fonte: INEP. Censo da Educação Superior 2018. Tabulação dos autores.

Constatou-se que 13.463 dos 72.408 universitários que entraram nos Institutos Federais em 2018 evadiram, ou seja, 18,59\% dos ingressantes naquele ano. Observa-se que dos universitários que evadiram em 2018, mais da metade ingressaram naquele ano ou no ano anterior (Gráfico 2). 
Gráfico 2: Ano de ingresso na instituição dos estudantes evadidos

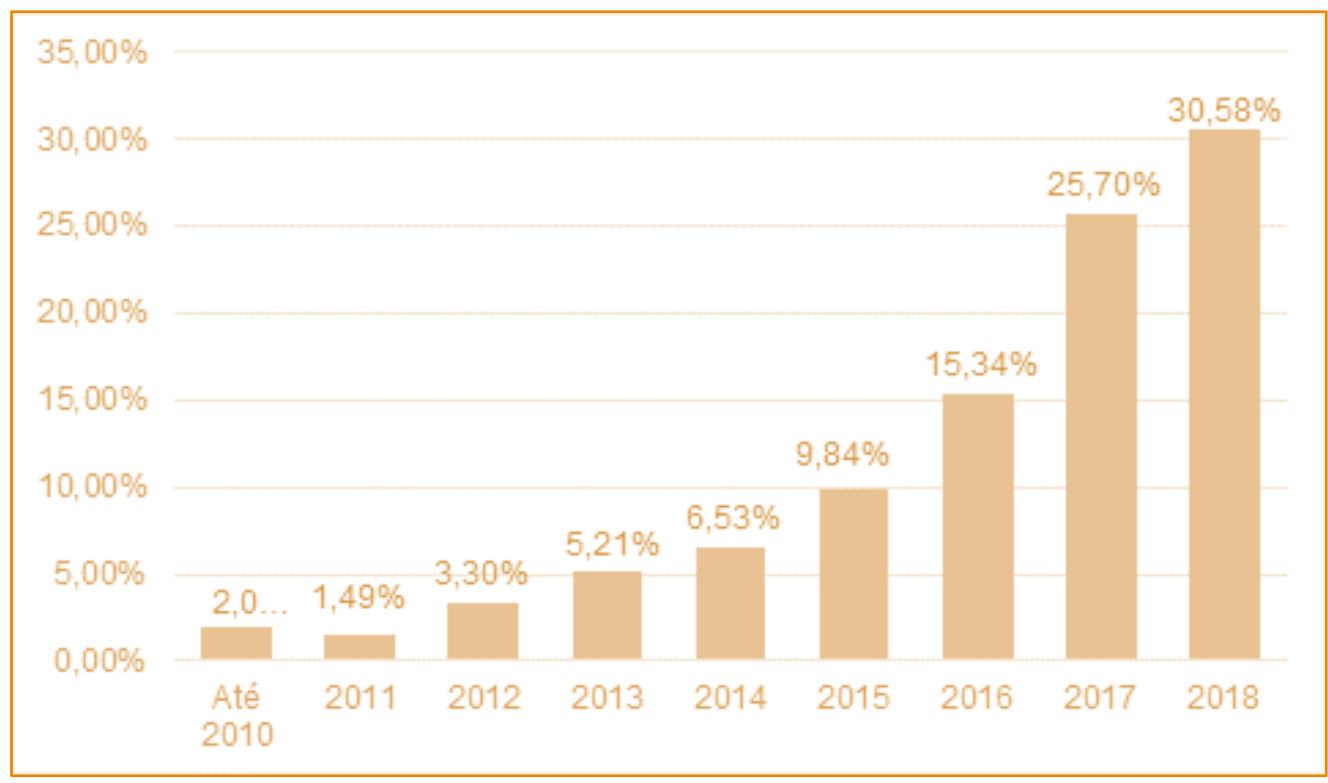

Fonte: INEP. Censo da Educação Superior 2018. Tabulação dos autores.

O resultado apresentado no Gráfico 2 corrobora com os estudos que apontaram que a evasão no ensino superior acontece com mais intensidade nos primeiros anos do curso (LI, 2016; SILVA FILHO et al, 2007; GUERRA, FERRAZ, MEDEIROS, 2019).

O estudo de Li (2016), que fez uma análise utilizando os dados do Censo da Educação Superior, indicou como um dos determinantes para o abandono do curso, a adesão ao Sistema de Seleção Unificada (SISU). Segundo a autora, esta participação aumenta a probabilidade da evasão acontecer no primeiro ano em 4,5 pontos percentuais.

Quanto ao tipo da rede de ensino na qual os universitários concluíram o ensino médio, $76,74 \%$ cursaram na rede pública, $21,74 \%$, na rede privada e $1,52 \%$ não informaram. No grupo dos estudantes que evadiram, $76,85 \%$ concluíram o ensino médio em instituições públicas, $21,75 \%$ em instituições privadas e ainda $1,40 \%$ não responderam. A proporção entre os estudantes evadidos e o total, em ambas as redes de ensino que estes cursaram o ensino médio, foi de 0,172.

Heringer (2018) destacou que muitos estudantes que ingressaram em uma universidade pública têm vivenciado dificuldades financeiras e também em termos do acesso às diversas oportunidades de inclusão em atividades oferecidas pelas universidades, algo que é um desafio institucional.

O apoio social existe como medida para auxiliar nos estudos e, nos dados do INEP, este benefício é apresentado como bolsa permanência, como bolsa trabalho, como apoio material didático, como apoio moradia ou como apoio transporte (INEP, $2019 b)$. No que se refere ao apoio social, $95,25 \%$ dos alunos que desistiram do curso 
não obtinham nenhum auxílio, enquanto 4,75\% recebiam. Li (2016) apresentou como resultado em seu estudo que o recebimento do apoio social tem impacto para reduzir a evasão nos primeiros anos do curso.

Outra medida visando a democratização do ensino superior foi a política de reserva de vagas. As cotas para o ingresso nas universidades públicas no Brasil foram implementadas de diferentes formas pelo país, através de iniciativas locais, como leis estaduais e deliberações de conselhos universitários até a Lei federal no 12.711/2012, que dispõe sobre a reserva de vagas das instituições federais à alunos oriundos integralmente do ensino médio público, pretos, pardos e indígenas (FERES JÚNIOR; DAFLON; CAMPOS, 2013). Nota-se pelo Gráfico 3 que a razão entre os evadidos e o grupo total dos alunos é menor entre os cotistas.

Gráfico 3: Proporção dos estudantes evadidos e do total que ingressaram por reserva de vagas

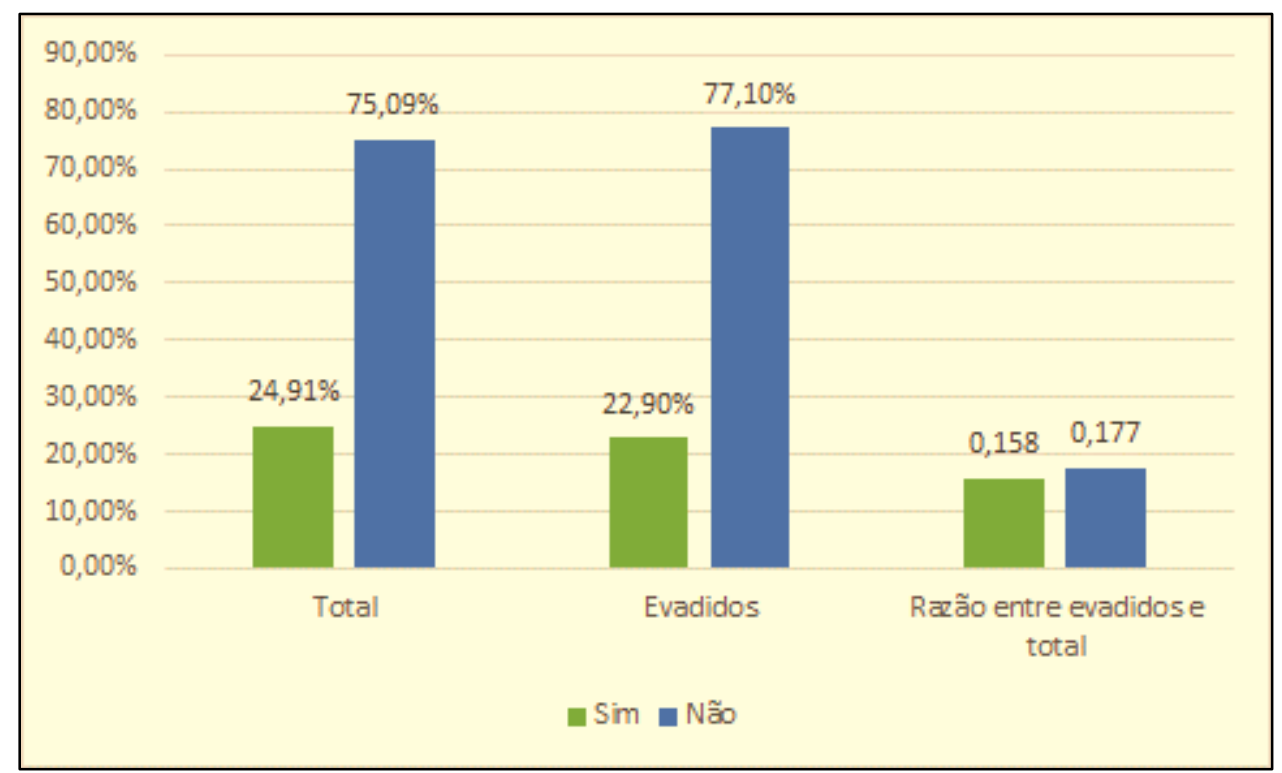

Fonte: INEP. Censo da Educação Superior 2018. Tabulação dos autores.

No estudo com os estudantes de graduação na Universidade Estadual do Rio de Janeiro (UERJ), Mendes Junior (2013) constatou que, em todos os níveis de dificuldade a evasão entre os não cotistas foi maior do que os cotistas.

A razão referente à reserva étnico racial é 0,165 (razão entre os evadidos que ingressaram por este tipo de reserva e o total), comparada às outras razões supracitadas (Gráfico 3) é menor.

Os cursos de graduação são agrupados em grande área, segundo o Manual para Classificação de Cursos de Graduação e Sequenciais: CINE Brasil 2018 do INEP. Os cursos estão divididos em dez áreas gerais, sendo essas: Educação, Artes e Humanidades, Ciências Sociais, Jornalismo e Informação; Negócios, Administração e Direito; Ciências Naturais, Matemática e Estatística; Computação e Tecnologias da Informação e Comunicação (TIC); Engenharia, Produção e Construção; Agricultura, Silvicultura, Pesca e Veterinária; Saúde e bem-estar e Serviços. A Tabela 6 informa 
sobre a evasão de acordo com estas áreas, indicando que a Computação e Tecnologias da Informação e Comunicação mostrou uma proporção maior.

Tabela 6: Evasão cursos de graduação por área de estudo

\begin{tabular}{|c|c|c|c|c|c|}
\hline Área & Total & $\%$ & Evadidos & $\%$ & $\begin{array}{l}\text { Razão de } \\
\text { evadidos } \\
\text { pelo total } \\
\text { por área } \\
\text { do curso }\end{array}$ \\
\hline Programas Básicos & 623 & $0,24 \%$ & 125 & $0,28 \%$ & 0,201 \\
\hline Educação & 80.178 & $31,32 \%$ & 14.371 & $32,65 \%$ & 0,179 \\
\hline Artes e Humanidades & 4.613 & $1,80 \%$ & 675 & $1,53 \%$ & 0,146 \\
\hline $\begin{array}{c}\text { Negócios, Administração } \\
\text { e Direito }\end{array}$ & 22.702 & $8,87 \%$ & 3.404 & $7,73 \%$ & 0,150 \\
\hline $\begin{array}{l}\text { Ciências Naturais, } \\
\text { Matemática e Estatística }\end{array}$ & 3.495 & $1,37 \%$ & 733 & $1,67 \%$ & 0,210 \\
\hline $\begin{array}{l}\text { Computação e } \\
\text { Tecnologias da } \\
\text { Informação e } \\
\text { Comunicação }\end{array}$ & 33.851 & $13,22 \%$ & 7.150 & $16,25 \%$ & 0,211 \\
\hline $\begin{array}{l}\text { Engenharia, Produção e } \\
\text { Construção }\end{array}$ & 74.117 & $28,95 \%$ & 12.576 & $28,57 \%$ & 0,170 \\
\hline $\begin{array}{l}\text { Agricultura, Silvicultura, } \\
\text { Pesca e Veterinária }\end{array}$ & 23.189 & $9,06 \%$ & 2.861 & $6,50 \%$ & 0,123 \\
\hline Saúde e Bem-Estar & 3.184 & $1,24 \%$ & 355 & $0,81 \%$ & 0,111 \\
\hline Serviços & 10.045 & $3,92 \%$ & 1.763 & $4,01 \%$ & 0,176 \\
\hline Total & 255.997 & $100,00 \%$ & 44.013 & $100,00 \%$ & 0,172 \\
\hline
\end{tabular}

Nota: A área Ciências Sociais, Jornalismo e Informação não apresentou nenhum curso.

Fonte: INEP. Censo da Educação Superior 2018. Tabulação dos autores.

Silva Filho et al (2007), quando analisaram os dados do INEP, calcularam a taxa de evasão média das oito áreas, divisão feita até então. O trabalho constatou que a área de Ciências, Matemática e Computação também era uma das que apresentava maior evasão.

Assim, pode-se perceber que existem alguns padrões nas proporções de evasão, que são influenciados por fatores internos ou externos às instituições.

\section{CONSIDERAÇÕES FINAIS}

A pesquisa foi realizada com o intuito de verificar as características dos estudantes dos cursos superiores dos Institutos Federais que evadiram no período mais recente. As razões que levam uma pessoa a abandonar um curso superior são as mais distintas, porém refletir sobre alguns padrões nos casos de evasão, pode auxiliar em medidas preventivas ou estratégicas para minimizar este fenômeno.

O presente estudo identificou que, apesar dos Institutos Federais possuírem nos seus cursos de graduação uma população de estudantes majoritariamente 
masculina, ao comparar as proporções de evasão dentro do mesmo grupo, a do sexo feminino é menor.

A região Centro-Oeste demonstra ter uma proporção maior de alunos que evadem e a Região Sul menor, enquanto as demais têm valores bem próximos.

Os ingressantes têm índices de evasão bem mais altos em relação aos outros estudantes que entraram na instituição nos anos anteriores, indicando que a chance de evadir logo no início da faculdade é maior. Apesar de existirem diversos fatores que resultam na desistência do curso, este percentual mais significativo também pode estar relacionado à escolha da carreira ou da instituição.

Altas taxas de evasão também é um problema que acontece na modalidade à distância, que apresentam uma razão entre os universitários evadidos e o total maior que os outros turnos.

Por se tratar de um estudo descritivo, algumas respostas precisariam de uma análise estatística mais complexa e como sugestão um estudo longitudinal, que fica como proposta para trabalhos futuros.

Visando uma educação inclusiva e de qualidade, uma das metas do quarto Objetivo do Desenvolvimento Sustentável (ODS) é que até o ano de 2030 faz-se necessário garantir a igualdade de acesso à população a educação técnica, profissional e superior de qualidade, incluindo a universidade (ONU, 2020). Ou seja, proporcionar a formação superior de qualidade a fim de que possa melhorar o acesso igualitário a um ensino que promova a mobilidade acadêmica, principalmente das camadas mais desprovidas da sociedade. Nesse sentido, é preciso pensar em estratégias não só de ingresso, mas de permanência principalmente para os estudantes menos favorecidos.

\section{REFERÊNCIAS}

ALMEIDA, O. C. S. et al. Evasão em cursos a distância: fatores influenciadores. Revista Brasileira de Orientação Profissional, v. 14, n. 1, p. 19-33, 2013.

BARDAGI, M.; HUTZ, C. S. Evasão universitária e serviços de apoio ao estudante: uma breve revisão da literatura brasileira. Psicologia Revista, v. 14, n. 2, p. 279301, 2005. Disponível em: $<$ https://revistas.pucsp.br/psicorevista/article/view/18107/13463 >. Acesso em: 09 jun. 2020.

BRASIL. Decreto № 6.096, de 24 de abril de 2007. Institui o Programa de Apoio a Planos de Reestruturação e Expansão das Universidades Federais - REUNI. Diário Oficial da União, Brasília, 25 abr. 2007. Disponível em: <http://www.planalto.gov.br/ccivil_03/_ato2007-2010/2007/decreto/d6096.htm>. Acesso em 28 abr. 2020.

BRASIL. Decreto № 7.234, de 19 de julho de 2010. Dispõe sobre o Programa Nacional de Assistência Estudantil - PNAES. Disponível em:<http://www.planalto.gov.br/ccivil_03/_ato2007-2010/2010/decreto/d7234.htm> Acesso em 12 maio 2020. 
BRASIL. Lei no 11.892, de 29 de dezembro de 2008. Institui a Rede Federal de Educação Profissional, Científica e Tecnológica, cria os Institutos Federais de Educação, Ciência e Tecnologia, e dá outras providências. Diário Oficial da União, Brasília, 30 dez. 2008. Disponível em:

<http://www.planalto.gov.br/ccivil_03/_ato2007-2010/2008/lei/l11892.htm>. Acesso em: 28 abr. 2020.

BRASIL. Ministério da Educação/Secretaria de Educação Profissional e Tecnológica (SETEC/MEC). Documento orientador para a superação da evasão e retenção na rede federal de educação profissional, científica e tecnológica. Brasília, 2014, 52 f. Disponível em: <http://r1.ufrrj.br/ctur/wp-

content/uploads/2017/03/Documento-OrientadorSETEC.pdf> Acesso em: 13 maio 2020.

BRASIL. Ministério da Educação/Secretaria de Educação Profissional e Tecnológica (SETEC/MEC). Portaria no 8, de 28 de maio de 2019. Institui e regulamenta a Comissão Permanente de Acompanhamento das Ações de Permanência e o Éxito dos Estudantes de Rede Federal e dá outras providências. Diário Oficial da União, Brasília 3 de jul. 2019 a. Disponível em:<http://www.in.gov.br/web/dou/-/portaria-n-8de-28-de-maio-de-2019-149876333>. Acesso em:13 maio 2020.

BRASIL. Ministério da Educação/Secretaria de Educação Profissional e Tecnológica (SETEC/MEC). Relatório Anual de Análise dos Indicadores de Gestão das Instituições Federais de Educação Profissional, Científica e Tecnológica Exercício 2018, SETEC/MEC, 2019b. Disponível em:

$<$ http://portal.mec.gov.br/docman/julho-2019-pdf/117321-caderno-de-indicadores2019-tcu/file>. Acesso em: 01 maio 2020.

BRASIL. Ministério da Educação. Institutos Federais de Educação, Ciência e Tecnologia: concepção e diretrizes. Brasília: MEC/SETEC, 2010. Disponível em: $<$ http://portal.mec.gov.br/index.php?option=com_docman\&view=download\&alias=66 91-if-concepcaoediretrizes\&category_slug=setembro-2010-pdf\&Itemid=30192> Acesso em: 13 jun. 2020.

BRASIL. Tribunal de Contas da União. Acórdão no 506/2013 -TCU. Plenário, de 13 de março de 2013. Brasília, DF: 13 de março de 2013 Disponível em:<https://pesquisa.apps.tcu.gov.br/\#/documento/acordaocompleto/*/KEY\%253AA CORDAOCOMPLETO1250021/DTRELEVANCIA\%2520desc/0/sinonimos\%253Dfals e> Acesso em: 13 maio 2020.

DIAS, E.C. M.; THEÓPHILO, C. R.; LOPES, M. A. S. Evasão no ensino superior: estudo dos fatores causadores da evasão no curso de Ciências Contábeis da Universidade Estadual de Montes Claros- Unimontes -MG. In: Congresso USP de Iniciação Científica em Contabilidade, São Paulo, SP. 2010.

FERES JÚNIOR, J.; DAFLON, V.T.; CAMPOS, L. A. Ações Afirmativas Raciais no Ensino Superior Público Brasileiro: um panorama analítico. Cadernos de Pesquisa, v. 43, n. 148, p. 302-327, jan. /abr., 2013. Disponível em: <http://www.scielo.br/pdf/cp/v43n148/15.pdf>. Acesso em: 20 abr. 2020.

GIL, A. C. Como elaborar projetos de pesquisa. 4. ed. São Paulo: Atlas, 2008. GUERRA, L. C. B.; FERRAZ, R. M. C.; MEDEIROS, J. P. Evasão na educação superior de um instituto federal do nordeste brasileiro. Revista Eletrônica de Educação, v. 13, n. 2, p. 533-553, 2019. 
HERINGER, R. Democratização da educação superior no Brasil: das metas de inclusão ao sucesso acadêmico. Revista Brasileira de Orientação Profissional, v. 19, n. 1, p. 7-17, 2018. Disponível em:<http://pepsic.bvsalud.org/pdf/rbop/v19n1/03.pdf> Acesso em: 28 abr. 2020.

INEP. Instituto Nacional de Estudos e Pesquisas Educacionais Anísio Teixeira Manual para classificação de cursos de Graduação e sequenciais: CINE Brasil 2018. Brasília: Inep, 2019a.

INEP. Instituto Nacional de Estudos e Pesquisas Educacionais Anísio Teixeira. Ministério da Educação. Microdados do Censo da Educação Superior 2018. Brasília: MEC/INEP, 2019b. Disponível em: <http://portal.inep.gov.br/web/guest/microdados > Acesso em: 12 abr. 2020.

INEP. Instituto Nacional de Estudos e Pesquisas Educacionais Anísio Teixeira. Censo da Educação Superior 2018: notas estatísticas. Brasília, 2019c.

Disponível em:

<http://download.inep.gov.br/educacao_superior/censo_superior/documentos/2019/c enso_da_educacao_superior_2018-notas_estatisticas.pdf>. Acesso em: 29 abr. 2020

KLEIN, R. Produção e utilização de indicadores educacionais: metodologia de cálculo de indicadores do fluxo escolar da educação básica. Revista Brasileira de Estudos Pedagógicos, v. 84, n. 206-07-08, 2003.

\section{LI, D. L. O novo ENEM e a plataforma SiSU: Efeitos sobre a migração e a} evasão estudantil. Dissertação de Mestrado, Programa de Pós-Graduação em Economia. Faculdade de Economia, Administração e Contabilidade, Universidade de São Paulo, São Paulo, 2016. Disponível em: $<$ https://teses.usp.br/teses/disponiveis/12/12138/tde-23112016094256/publico/CorrigidaDenise.pdf> Acesso em: 07 maio 2020.

LIMA, F. B.G. A Formação de Professores nos Institutos Federais: perfil da oferta. Revista Eixo, v. 2, n. 1, p. 83-105, 2013. Disponível em: <http://revistaeixo.ifb.edu.br/index.php/RevistaEixo/article/view/104/52> Acesso em 14 jun. 2020.

LOBO, M. B. C. M. Panorama da evasão no ensino superior brasileiro: aspectos gerais das causas e soluções. Associação Brasileira de Mantenedoras de Ensino Superior. Cadernos, v. 25, 2012.Disponível em:

<http://www.institutolobo.org.br/imagens/pdf/artigos/art_087.pdf>. Acesso em: 28 abr. 2020.

MELO, H. P. Gênero e a perspectiva regional na educação superior brasileira" In Simpósio Gênero e Indicadores da Educação Superior Brasileira. Brasília: INEP, 2008. Disponível em: <http://portal.inep.gov.br/informacao-da-publicacao//asset_publisher/6JYlsGMAMkW1/document/id/492372>. Acesso em: 06 maio 2020.

MENDES JUNIOR, A. A. F. Uma análise da progressão dos alunos cotistas sob a primeira ação afirmativa brasileira no ensino superior: o caso da Universidade do Estado do Rio de Janeiro. Ensaio: aval. pol. públ. Educ., Rio de Janeiro, v.22, n. 82, p. 31-56, jan. /mar. 2014, p. 31-56. Disponível em: <http://www.scielo.br/pdf/ensaio/v22n82/a03v22n82.pdf.> Acesso em: 29 abr. 2020.

MOORE, M.; KEARSLEY, G. Educação a Distância: uma visão integrada. São Paulo: Thomson Pioneira, 2008. 
MORAES, G. H. et al. Plataforma Nilo Peçanha: guia de referência metodológica. Brasília/DF: Editora Evobiz, 2018.

ONU. Organização das Nações Unidas. Transformando Nosso Mundo: A Agenda 2030 para o Desenvolvimento Sustentável. Disponível em:

<https://nacoesunidas.org/pos2015/ods4/ >. Acesso em 12 jun. 2020.

OTRANTO, C. R. Criação e implantação dos Institutos Federais de Educação, Ciência e Tecnologia-IFETs. Revista Retta, n. 1, p. 89-110, 2010. Disponível em: $<$ http://www.ia.ufrrj.br/ppgea/conteudo/Retta/N01-2010.pdf\#page=88>. Acesso em: 10 jun. 2020.

PLATAFORMA NILO PEÇANHA. Rede Federal de Educação profissional Científica e Tecnológica. SETEC/MEC. Disponível em:

<http://plataformanilopecanha.mec.gov.br/>. Acesso em: 29 abr. 2020.

SENKEVICS, A. S.; MACHADO, T. S.; OLIVEIRA, A. S. A cor ou raça nas estatísticas educacionais: uma análise dos instrumentos de pesquisa do INEP. Brasília, DF: INEP, 2016. 48 p. (Texto para Discussão no 41).

SILVA FILHO, R. L. L. et al. A evasão no ensino superior brasileiro. Cadernos de pesquisa, v. 37, n. 132, p. 641-659, 2007. Disponível

em:<https://www.scielo.br/scielo.php?pid=S0100-

15742007000300007\&script=sci_arttext> Acesso em: 25 abr. 2020.

SOUZA, E. Política de reserva de vagas nas universidades públicas: uma análise do perfil dos estudantes e escolha de carreira, 2015, 193 f. Dissertação (Mestrado em Estudos Populacionais e Pesquisas Sociais). Escola Nacional de Ciências Estatísticas. - Rio de Janeiro, 2015.Disponível em:<http://www.ence.ibge.gov.br/images/ence/doc/mestrado/dissertacoes/2015/Diss ertacao_Elisangela.pdf>. Acesso em: 2 jun. 2020.

SOUZA, F. C. S.; SILVA, S.H. S. C. Institutos Federais: expansão, perspectivas e desafios. Revista Eletrônica Científica Ensino Interdisciplinar, v. 2, n. 5, p. 17-26, 2016. Disponível em:

<http://periodicos.uern.br/index.php/RECEl/article/view/1949/1048>. Acesso: 10 jun. 2020. 